\title{
A Study on Mental Health Profile of Athletes and Technical Staff of Iranian Women's National Swimming Team
}

\author{
Sholeh khodadad kashi \\ Assistant professor, K.N. Toosi University of technology \\ *Corresponding Author: Sholeh khodadad kashi, Assistant professor, K.N. Toosi University of technology
}

\begin{abstract}
Various factors influence on mental health which among them are exercise and physical activity; regarding the close relationship that exists between these two categories. The aim of this study was to investigate the mental health of female athletes and technical staff of the national swimming team. The research method used in this study was descriptive-survey method.The study population included all swimmers and technical staff of the national team that 68 people were selected out of them using purposive sampling method. The measurement instrument of Mental Health was Minnesota Multiphasic Personality Inventory-2-Restructured Form which has been validated in Iran.After completing the questionnaires and extracting the data, mental health profile was traced using standard T Mc Gall scores and standard cut-off points of quartile deviation. Then, data figures were shown through percentage and frequency distribution tables. The research results showed that athletes and technical staff of the national swimming team in clinical scales including cerebration disorder, persecutory and harassment delusions, and strange experiences as well as in specific problem scales including fears limiting a behavior have a mean higher than theexercisenorm of a society and need individual and group counseling. It should be noted that no problem was observed in other scales and about 70 percent of the samples showed no disorder in mentioned scales.
\end{abstract}

Keywords: Mental health, Female swimmers and Iran's national team.

\section{INTRODUCTION}

Science of psychology has dedicated various disciplines and branches to itself that can be divided in two fundamental and applied groups. The applied psychology is used in order to improve living standards. Sport Psychology is one of the applied disciplines in the science of psychology that attempts to close athlete's situation to the desired level using the principles of psychology ${ }^{[7]}$. In sport psychology, it is tried to create a better performance for the athletes using principles and texts of psychology. Nowadays, sport psychologists are trying to close to athletes' excitement level to an optimal level using psychological theories concerned with motivation and emotion domains. Additionally, sport psychologists are trying to identify the effects of exercise on personality traits , and even in some cases, exercise is used as a process for mental health rehabilitation and treatment of mental disorders ${ }^{[16]}$. There is a close relationship between Sport and mental health, mental health is influenced by several factors, regular exercise activities not only reduces anxiety and depression, but also increases self-esteem ${ }^{[1]}$.On the other hand, nowadays, physical activity and sport has found a main position in human being's social life and not only culturally and leisurely but also economically socially, and politically has a critical, substantial and notable role; because on the one hand, many jobs are created in parallel to physical activity and sport and its related factors and on the other hand, sport is considered a job, especially professionally. Moreover, inhibitory effects of sport in relation to corruptions and social offenses and its driving effects in creating a solidarity, unity, effort and socialization spirit as well as culture making, is regarded as a valuable issue. Also, since the sport has had an increasing growth in recent decades and has become a phenomenon with global importance, especially in the past twenty to thirty years, Analysts go forward insomuch consider sport as intersection of all humanity and evolved from of entrepreneurship competition or even like Pierre De Coubertin, the father of Olympics, who knows sport" as a brightest flame which burns in the human heart" ${ }^{[5]}$.

Therefore, sport contributes greatly to establishment of security as well as psychological and social peace for individuals and communities and provide health and healthy living. The effect of sensory 
motor skills and physical activity on mental actions and mental evolution is such that many psychologists and education experts believe that such activities must primarily be a part of ordered educational programs. Scholars' familiarity with different programs and methods concerned with sensory and motor activities, not only causes their mental acts, but also creates mental freshness and vitality, strengthen the confidence and therefore provides their mental health ${ }^{[6]}$.

In psycho-social factors domain of exercise, a great attention must be paid on the necessity of exercise phenomenon and it should be tried to make spirit of heroism dominant on all dimensions. In other words, professional sport on the one hand must be able to meet the needs of a society and on the other hand, it has to complete dimensions of heroism. In this regard, identifying the mental health of athletes in swimming is considered as unfolded paths that can determine sports policy and provides basic information for sport programmers. Development of heroism databases is known as one of the priorities of the Ministry of Sport and Youth that this priority is in Cultural Development Program and can be fruitful using capabilities of national team athletes and coaching staff.

Studies conducted in this field show that sport, in addition to being a valuable tool for physical health, has a close relationship with mental health and particularly prevention of mental disorders. According to Hughes, athletes often feel less anxiety and depression compared to sedentary people. In a review study which was carried out on a large number of studies investigating the effects of exercise on anxiety and personality traits, it was found that exercise has a balance making impact on treatment of acute and chronic depressions and the highest stress reduction was concerned with people who needed clinical treatment (North, 1990; vehicles and Stevens, 1994).Other studies indicate similar effects of exercise on mental states in specific circumstances. For example, Madeleine (1996) studied effect of eliminating exercise on ten volunteers. They trained 6 to 7 days per week and averagely 45 minutes per day. They rested for three days after a day of exercise and resumed exercise in fifth day. Reducing and eliminating exercise sessions was associated with side effects such as disorder increase in selfassessment, anxiety, stress, depression, confusion and reducing individuals' power. These effects were opposite when exercise resumed ${ }^{[11]}$.

Very extensive researches have been conducted in Europe and America on athletes' mental health, psychological and exercise skills, goal setting in sport, motivation and exercise, effect of exercise on reducing anxiety and depression, stress, aggression and increase of attention and focus, selfconfidence, mental imagery and interactive skills, personality and exercise. For example, Morgan (2002) has reported role of emotions in physical activities; Kobasa (2003) about stress reduction and increase in physical activity, Crews \& Landers (2003) on less psychological response and psychological pressures caused by exercise; Jones (2004) about impact of psychological skills in physical activities; Wax (2006) on reduction of depression and aggression caused by sport, Landers et al (2006) on reduction of anxiety as a result of continuous and intense physical activity and Segal (2008) on the effect of cognitive and cognitive skills on enhancing athletic performance and the role of exercise in increasing the focus on athletes ${ }^{[12]}$.In a study carried out by Kamkari and Shokrzadeh (2007) comparing personality traits and hardiness of professional and amateur basketball players, it was found that professional athletes enjoy higher extroversion compared to amateur athletes. With an increase in the personality trait of amiability, hardiness trait also increases in professional and amateur athletes ${ }^{[14]}$.In another study by Wiener (2007), entitled study of athletes and non-athletes' personality traits, it is indicated that athletes enjoy higher internal locus of control and the lower amount of pride, embarrassment and shame compared to non-athletes ${ }^{[19]}$.

Williams, in a research project that studied personality traits of successful professional and pioneer female athletes, came to the conclusion that women who participated in the America Olympic team in 1964 in individual sports were more mastery-oriented, aggressive, adventurous, sensitive, independent, self-sufficient and more introverted compared to women who participated in team sports. Female athletes in general were impose, dominant, self-sufficient, conservative, progressivist and intelligent and were moderate or low emotionally ${ }^{[18]}$.

The results of a research showed that psychological traits and particularly mental health are major factors determining professional athletes' sport attitudes and behaviors (Pydmont, Hill \& Blanco, 1999, David \& Meg, 1994, Nikkokam \& Boil, 1995). For example, it is assumed that introverts feel extra arousal sooner than extraverts and are more anxious and thus have poorer performance. However, all research results are not consistent or researches have shown that being impulsive (a combination of 
Eysenck's extraversion and neuroticism) can be considered as one of the most important personality variables. In this way, those who are more impulsive become excited late in the day, but those who are less impulsive become excited in early hours of the day. This issue has particular consequences for performance. For example, an athlete whose impulsiveness is high, needs a greater relaxation and stress reduction in the evening matches compared to matches which are held in the morning. This represents the relationship between personality traits, emotional intelligence and cognitive intelligence ${ }^{[8]}$. Hence, in Sport Psychology, it is tried to create a better performance for the athletes by using psychology texts. Nowadays, sport psychologists are trying to close athletes' stimulation level to an optimal level using psychological theories. Besides that, sport psychologists are trying to identify effects of exercise on personality traits and mental health, and even in some cases, exercise is use as a process to improve treatment of mental disorders and improvement of mental health ${ }^{[17]}$.

So, since cognitive and personality traits are very important and effective factors in determining sport performance of professional athletes in different situations, importance of this factor and its infrastructure is such that massive amounts of researches have been carried out about it. In this regard, Jones (b. 1995, a 1995, 1991) argues that cognitive and personality traits can have both positive and negative effects on athletic performance. In addition, psychological traits beside the extension of capabilities of science of psychology in enhancing athletes' performance and their mental health, they can provide a practical path for sport psychologists' action in sport disciplines. Also, with regard to the fact that coaches are often concerned about the status of their athletes before and during the race, by identifying psychological factors affecting athletic performance, they try to provide conditions for athletes in order to achieve peak sport performance ${ }^{[4]}$.

In the research carried out by Moradinejad (2003), which was about effects of physical activity on adolescents' mental health, it was found that exercise increases people's mental health ${ }^{[15]}$. In a study by Ascoli and Crimea (2001), the relationship between physical activity and self-concept in athletes and non-athletes was investigated among 470 people and it was determined that athletes who participated in endurance activities, had less depression, anxiety and antisocial behaviors compared to other athletes (13).In the research conducted by Dai and Carol (2004) which individual and team performance has been predicted through emotional intelligence and mental skills and abilities, it has been raised that emotional intelligence, mental skills and Mental Health can enhance athletes' performance ${ }^{[19]}$. In a study by Sadeghi (2007) which was carried out on 80 students, including 40 athletes and 40 non-athletes, their physical fitness and maximum aerobic power was investigated via step test. The results showed that the difference between correlation of female athlete and non-athlete students' mental health and physical fitness was not significant ${ }^{[10]}$.

Finally, it is stated that several studies have been conducted in the field of exercise and mental health, but little research has been carried out regarding professional sport and it has been argued in some of these researches that mental health in professional athletes, unlike other studies, is lower than nonathletes. Therefore, it cannot yet be accurately determined whether exercise increases mental health or decreases mental health in professional athletes. Therefore, theoretical vacuum on the mental health of female athletes and technical staff of swimming team led to conduction of the present study and the aim of this study was to investigate mental health profile of female athletes and technical staff of national swimming team that in this direction, factors such as profile of clinical scales, profile of special problem scales and profile of pathology of personality in female athletes in the national team and technical staff were studied.

\section{MethodologY}

Since subject of the research has focused on investigating mental health profile of female athletes of the national swimming team and technical staff and none of the variables were manipulated and only the relationship between the variables was investigated, research method is survey which fits within the descriptive methods.

The study population included all national team swimmers and technical staff that 68 people were selected out of them using purposive sampling method. Considering that access to all population was possible, statistical population fits within finite populations.

The measurement tool for evaluation of mental health was Minnesota Multiphasic Personality Inventory-2-Restructured Form (MMPI-2-RF) structured by HoteWee and McCain Lee (2008) that its reliability has been validated in Iran by Kamkari \& Shokrzadeh (2011). With regard to the structure of 
instrument, it can be stated that Minnesota Multiphasic Personality Inventory-2-Restructured Form (MMPI-2-RF) contains 50 Stowe scales with 8 validity scales, 12clinical scales, 25 special problem scales and 5 personality pathology scales. Validity scalesinclude contradiction of variable responses, contradiction of correct responses, uncommon responses, and uncommon psychopathological responses, validity of complications, uncommon piety and compatibility validity. Regarding Clinical Scales, three first grade or higher level clinical scales are considered as alexithymia/internalization, cerebration disorder and behavior/externalization disorder. Then, 9 main clinical scales are declared as low morale, somatization, low positive emotions, pessimism, anti-social behavior, harassment and persecutory delusions, negative disruptive emotions, strange experiences and hypomanicsomatotonia. Then, with regard to the profile of specific problems, 25 scales are stated including adolescent conduct problems, substance abuse, aggression, somatization, family problems, interpersonal passiveorientation, social avoidance, shyness, lack of connectionism, literary/aesthetic interests, mechanical /physical interests, illness, gastrointestinal complaints, headache complaints, neuropsychology complaints , cognitive complaints, death/suicide delusions, helplessness/desperation, self-doubt, inefficiency, mental stress/anxiety, anxiety, anger capacity, behavior limiting phobias, multiple phobias. Finally, considering the pathology personality, 5 scales namely aggression, psychosis, unresponsiveness, neurosis/negative emotions, introversion/low positive emotions. It should be noted that the mentioned tool has external, face, content validity (validity scales, clinical scales, internalization scales, physical-cognitive, externalization scales, interpersonal and interests), construct validity (using confirmatory factor analysis) and concurrent validity (correlation with Million Inventory - 3).

Reliability coefficients in above scales are higher than 0.85 . So, a wide range of profiles have been offered for 8 validity scales, three first grade clinical scales, 9 original clinical scales, 25 special problem scales and 5 personality pathology scales that based on 338 two-option questions, raw scores have become standard scores with zero-one keying and lack of nervousness, mild nervousness and severe nervousness are observed. After completing the questionnaires and extracting the data, mental health profile was traced using standard $\mathrm{T}$ Mc Gall scores and standard cut-off points of quartile deviation. Then, data figures were shown through percentage and frequency distribution tables.

\section{FINDINGS}

Findings obtained from statistical analysis of survey data in conjunction with clinical scales, special problems and personality pathology in female athletes and technical staff of national swimming team has been provided in Tables 1, 2 and 3 completely.

Table1. Study of clinical scales of female athletes and technical staff of the national swimming team

\begin{tabular}{|c|c|c|c|c|c|c|}
\hline \multirow{2}{*}{ clinical scales } & \multicolumn{2}{|c|}{ Severe disorder } & \multicolumn{2}{c|}{ Mild disorder } & \multicolumn{2}{c|}{ absence of disorder } \\
\cline { 2 - 7 } & frequency & percentage & frequency & percentage & frequency & percentage \\
\hline alexithymia & $\mathbf{2 2}$ & $\mathbf{3 2 / 4}$ & $\mathbf{1 0}$ & alexithymia & $\mathbf{2 2}$ & $\mathbf{3 2 / 4}$ \\
\hline $\begin{array}{c}\text { cerebration } \\
\text { disorder }\end{array}$ & $\mathbf{2 6}$ & $\mathbf{3 8} / 2$ & $\mathbf{6}$ & $\begin{array}{c}\text { cerebration } \\
\text { disorder }\end{array}$ & $\mathbf{2 6}$ & $\mathbf{3 8} / \mathbf{2}$ \\
\hline $\begin{array}{c}\text { Behavioral } \\
\text { disorder }\end{array}$ & $\mathbf{3 1}$ & $\mathbf{4 5 / 6}$ & $\mathbf{4}$ & $\begin{array}{c}\text { Behavioral } \\
\text { disorder }\end{array}$ & $\mathbf{3 1}$ & $\mathbf{4 5 / 6}$ \\
\hline low morale & $\mathbf{2 2}$ & $\mathbf{3 2 / 4}$ & $\mathbf{8}$ & low morale & $\mathbf{2 2}$ & $\mathbf{3 2} / \mathbf{4}$ \\
\hline somatization & $\mathbf{2 3}$ & $\mathbf{3 3 / 8}$ & $\mathbf{6}$ & somatization & $\mathbf{2 3}$ & $\mathbf{3 3 / 8}$ \\
\hline $\begin{array}{c}\text { low positive } \\
\text { emotions }\end{array}$ & $\mathbf{3 5}$ & $\mathbf{5 1 / 5}$ & $\mathbf{6}$ & $\begin{array}{c}\text { Low positive } \\
\text { emotions }\end{array}$ & $\mathbf{3 5}$ & $\mathbf{5 1 / 5}$ \\
\hline pessimism & $\mathbf{2 8}$ & $\mathbf{4 1 / 2}$ & $\mathbf{9}$ & pessimism & $\mathbf{2 8}$ & $\mathbf{4 1 / 2}$ \\
\hline $\begin{array}{c}\text { anti-social } \\
\text { behavior }\end{array}$ & $\mathbf{2 3}$ & $\mathbf{3 3 / 8}$ & $\mathbf{5}$ & $\begin{array}{c}\text { anti-social } \\
\text { behavior }\end{array}$ & $\mathbf{2 3}$ & $\mathbf{3 3 / 8}$ \\
\hline $\begin{array}{c}\text { harassment and } \\
\text { persecutory } \\
\text { delusions }\end{array}$ & $\mathbf{3 2}$ & $\mathbf{4 7 / 1}$ & $\mathbf{6}$ & $\begin{array}{c}\text { harassment and } \\
\text { persecutory } \\
\text { delusions }\end{array}$ & $\mathbf{3 2}$ & $\mathbf{4 7 / 1}$ \\
\hline $\begin{array}{c}\text { negative disruptive } \\
\text { emotions }\end{array}$ & $\mathbf{2 9}$ & $\mathbf{4 2 / 6}$ & $\mathbf{8}$ & $\begin{array}{c}\text { negative } \\
\text { disruptive } \\
\text { emotions }\end{array}$ & $\mathbf{2 9}$ & $\mathbf{4 2 / 6}$ \\
\hline $\begin{array}{c}\text { strange } \\
\text { experiences }\end{array}$ & $\mathbf{2 4}$ & $\mathbf{3 5 / 3}$ & $\mathbf{7}$ & $\begin{array}{c}\text { strange } \\
\text { experiences }\end{array}$ & $\mathbf{2 4}$ & $\mathbf{3 5 / 3}$ \\
\hline
\end{tabular}


A Study on Mental Health Profile of Athletes and Technical Staff of Iranian Women's National Swimming Team

As seen in Table1, 51.5 percent of female athletes and technical staff of swimming team have low positive emotions, 51.5 percent with hypomanic somatotonia and 47.1 percent have severe harassment and persecutory delusions.

Table2. Study of specific problems of women's national swimming team athletes and coaching staff

\begin{tabular}{|c|c|c|c|c|c|c|}
\hline \multirow{2}{*}{$\begin{array}{c}\text { specific } \\
\text { problem scales }\end{array}$} & \multicolumn{2}{|c|}{ Severe disorder } & \multicolumn{2}{|c|}{ Mild disorder } & \multicolumn{2}{|c|}{ absence of disorder } \\
\hline & frequency & percentage & frequency & percentage & frequency & percentage \\
\hline illness & 29 & $42 / 6$ & 5 & illness & 29 & $42 / 6$ \\
\hline $\begin{array}{l}\text { gastrointestinal } \\
\text { complaints }\end{array}$ & 34 & 49 & 8 & $\begin{array}{l}\text { gastrointestinal } \\
\text { complaints }\end{array}$ & 34 & 49 \\
\hline $\begin{array}{l}\text { headache } \\
\text { complaints }\end{array}$ & 24 & $35 / 3$ & 10 & $\begin{array}{l}\text { headache } \\
\text { complaints }\end{array}$ & 24 & $35 / 3$ \\
\hline $\begin{array}{l}\text { neuropsychology } \\
\text { complaints }\end{array}$ & 20 & $29 / 4$ & 6 & $\begin{array}{l}\text { neuropsychology } \\
\text { complaints }\end{array}$ & 20 & $29 / 4$ \\
\hline $\begin{array}{l}\text { cognitive } \\
\text { complaints }\end{array}$ & 29 & $42 / 6$ & 6 & $\begin{array}{l}\text { cognitive } \\
\text { complaints }\end{array}$ & 29 & $42 / 6$ \\
\hline $\begin{array}{l}\text { death / suicide } \\
\text { delusions }\end{array}$ & 34 & 49 & 8 & $\begin{array}{c}\text { death / suicide } \\
\text { delusions }\end{array}$ & 34 & 49 \\
\hline $\begin{array}{c}\text { helplessness / } \\
\text { desperation }\end{array}$ & 11 & $16 / 2$ & 10 & $\begin{array}{c}\text { helplessness / } \\
\text { desperation }\end{array}$ & 11 & $16 / 2$ \\
\hline self-doubt & 16 & $23 / 5$ & 9 & self-doubt & 16 & $23 / 5$ \\
\hline inefficiency & 38 & $55 / 9$ & 5 & inefficiency & 38 & $55 / 9$ \\
\hline $\begin{array}{l}\text { mental stress / } \\
\text { anxiety }\end{array}$ & 38 & $55 / 9$ & 5 & $\begin{array}{l}\text { mental stress / } \\
\text { anxiety }\end{array}$ & 38 & $55 / 9$ \\
\hline anxiety & 34 & 49 & 8 & anxiety & 34 & 49 \\
\hline anger capacity & 34 & 50 & 6 & anger capacity & 34 & 50 \\
\hline $\begin{array}{c}\text { behavior } \\
\text { limiting phobias }\end{array}$ & 29 & $42 / 6$ & 10 & $\begin{array}{c}\text { behavior } \\
\text { limiting phobias }\end{array}$ & 29 & $42 / 6$ \\
\hline $\begin{array}{c}\text { multiple specific } \\
\text { phobias }\end{array}$ & 40 & $58 / 8$ & 2 & $\begin{array}{c}\text { multiple specific } \\
\text { phobias }\end{array}$ & 40 & $58 / 8$ \\
\hline $\begin{array}{c}\text { adolescent } \\
\text { conduct } \\
\text { problems }\end{array}$ & 32 & $47 / 1$ & 9 & $\begin{array}{c}\text { adolescent } \\
\text { conduct } \\
\text { problems }\end{array}$ & 32 & $47 / 1$ \\
\hline substance abuse & 26 & $38 / 2$ & 3 & substance abuse & 26 & $38 / 2$ \\
\hline aggression & 36 & $52 / 9$ & 3 & aggression & 36 & $52 / 9$ \\
\hline somatization & 33 & $48 / 5$ & 6 & somatization & 33 & $48 / 5$ \\
\hline family problems & 40 & $58 / 8$ & 2 & family problems & 40 & $58 / 8$ \\
\hline $\begin{array}{c}\text { interpersonal } \\
\text { passive- } \\
\text { orientation }\end{array}$ & 32 & $47 / 1$ & 8 & $\begin{array}{c}\text { interpersonal } \\
\text { passive- } \\
\text { orientation } \\
\end{array}$ & 32 & $47 / 1$ \\
\hline social avoidance & 26 & $38 / 2$ & 6 & social avoidance & 26 & $38 / 2$ \\
\hline shyness & 15 & $22 / 1$ & 11 & shyness & 15 & $22 / 1$ \\
\hline
\end{tabular}

Based on the results obtained from the study (Table 2),among female athletes and technical staffof national swimming team, 58.8 percent have specific multiple phobias, 58.8 percent have family problems, 55.9 percent have inefficiency, 55.9 percent have mental pressure - anxiety and 58.8 percent of them have severe mechanical / physical interests.

Table3. Study of personality pathology of women's national swimming team athletes and coaching staff

\begin{tabular}{|c|c|c|c|c|c|c|}
\hline \multirow{2}{*}{$\begin{array}{c}\text { personality } \\
\text { pathology scales }\end{array}$} & $\begin{array}{c}\text { Severe } \\
\text { disorder }\end{array}$ & $\begin{array}{c}\text { Mild } \\
\text { disorder }\end{array}$ & $\begin{array}{c}\text { absence of } \\
\text { disorder }\end{array}$ & $\begin{array}{c}\text { personality } \\
\text { pathology scales }\end{array}$ & $\begin{array}{c}\text { Severe } \\
\text { disorder }\end{array}$ & $\begin{array}{c}\text { Mild } \\
\text { disorder }\end{array}$ \\
\hline & frequency & percentage & frequency & frequency & frequency & percentage \\
\hline aggression & 28 & $41 / 2$ & 4 & aggression & 28 & $41 / 2$ \\
\hline psychosis & 19 & $27 / 9$ & 10 & psychosis & 19 & $27 / 9$ \\
\hline unresponsiveness & 34 & 50 & 5 & unresponsiveness & 34 & $\mathbf{5 0}$ \\
\hline neurosis & 28 & $41 / 2$ & 6 & neurosis & 28 & $41 / 2$ \\
\hline introversion & 36 & $52 / 9$ & 4 & introversion & 36 & $52 / 9$ \\
\hline
\end{tabular}


As shown in Table3, 50 percent of swimming team female athletes and technical staff have unresponsiveness and 52.9 percent of them has extreme introversion and in other subscales there is not much disorder.

\section{DISCUSSION AND CONCLUSION}

Experts in the field of sport psychology believe that exercise and physical activity can improve and promote athletes' different personality aspects (20). Many studies have been conducted in this field and has demonstrated positive effect of physical activity on some personality and emotional traits. For example, in a research by Aslankhani and Shahidi (1999), psychological traits of athletes was significantly better than non-athletes' ${ }^{[2]}$.Among other studies, studies by Brown et al (1995), Page et al (1995), Finkenberg and Mood (1996) can be pointed out that have confirmedthis issue. In contrast, many researchers came to different conclusions like studyby Fisher et al. (1996) and Foster (1997). Their results showed that participation in physical activity and sport in itself has no impact on psychological traits ${ }^{[9,20]}$.

Another important factor in athletic success is athlete's personality profile. Sport Psychologists, have allocated considerable studies to the issue of athletes' personality profile ${ }^{[3]}$. Personality Profile is an important issue; because, athletes even when they have similar skills, have a different function and it is unclear which personality trait leads to athletes' success. Some athletes, despite bearing extreme pressure, have acceptable performances, while some athletes, even professional athletes, have not desirable performances in certain psychological circumstances and environmental changes. This indicates the effect of different psychological and personality aspects of an athlete on his performance ${ }^{[3]}$.The study of feelings, emotions and mental health in sport Psychology is important for two main reasons from theoretical and applied perspective. First, it seems that it directly or indirectly affects athletic performance (Hanin, 1999; Lane and Terry, 2000). Second, through which it provides basic information related to itin association with athlete - environment (Lazarus, 1999) such as importance of sporting event, capability of overcoming reactive emotions and desires ${ }^{[17]}$.

Findings of this research showed that athletes of national swimming team and coaching staff in the clinical scales have a "low positive emotions," "hypomanic somatotonia" and "harassment and persecutory delusions" and in specific problems scales have " certain multiple phobias ", "family problems "" inefficiency "and" psychological pressure - anxiety "and in personality pathology scales, are" irresponsible ". Therefore, it is recommended to take advantages of individual and group counseling classes in order to reduce and eliminate mentioned scales. It should be noted that no severe disorder or problems is observed in other scales and about $70 \%$ of the samples in mentioned scales show absence of disorder that indicates that swimmers and coaching team of national team enjoy a relatively favorable personality profile.

By comparing results of this study and literature of researches inside and outside the country, results of this study are consistent with Kamkari and Shokrzadeh's (1386) which compares personality traits and hardiness of professional and amateur basketball players which states that professional athletes enjoy higher extraversion ${ }^{[14]}$. It is also in line with R Wiener's (2007), entitled a study on personality traits of athletes and non-athletes which indicates that athletes have higher internal locus of control and the degree of pride, embarrassment and shame is lower than non-athletes ${ }^{[19]}$. It is also aligned with a study which Williams (2005) carried out on professional female athletes and protagonists' personality traits and generally concluded that female athletes are procrustean, predominant, selfsufficient, cautious, progressivist and intelligent and are moderate or low in terms of emotional feelings. The results of the present study are consistent with the results of the study by Navvabinrjad (1378) on recognition of the effects of exercise on mental health and personality traits of elite chess players as well as the research by Moradinejad (1382) in relation to the effects of physical activity on adolescents' mental health. The results of mentioned studies showed that sport activities contribute to the promotion of subjects' mental health ${ }^{[15]}$.

The results of the study by Skouly \& Carimeh (2001) about the relationship between physical activity and self-imagination of athletes and non-athletes demonstrated that athletes, who participated in endurance activities, have less depression, anxiety and antisocial behavior compared to non-athletes 
${ }^{[13]}$. The research conducted by Day \& Carroll (2004) about prediction of individual and team performance through emotional intelligence and mental skills and abilities argues that emotional intelligence, mental skills and mental health can lead to athletes' better performance (22). It is coordinated and consistent with the research carried out by Sadeghi (1386), about the effectiveness of aerobic exercise on athletes and non-athletes;thus, in all the researches it is indicated that doing exercise can lead to mental health promotion ${ }^{[10]}$.Therefore, it is concluded that information obtained from the study of psychological profile is very essential in order to better understanding of athletes' promoting programs in concerned with behavior, decision making and performance as well as advancing athletes' psychological improvement ${ }^{[21]}$.

\section{REFERENCES}

[1] Ahula, A., Hetfield, B. (1997). "Sport Psychology with a mental, social approach," Translated by Reza Fallah and Mohsen Hajilou, First Edition, Tehran, Physical Education Organization Publication, Deputy of Educational and Cultural Affairs, Office of Research and Education.

[2] Aslankhani, MA.,Shahidi, SH. (1999). "Study and comparison of a selection of athlete and non-athlete male and female students' psychological traits, universities covered by the Ministry of Culture and Higher Education located in Tehran". Olympic, Volume 1, Issue 3 (Successive Number 3), autumn and winter 1999, pp. 57-78.

[3] Akbari, P. (2011). "Theeffects of Personality Profile and intelligence profile on the performance of elite volleyball athletes," MA thesis, Islamic Azad University of Tehran.

[4] Basharat, M.A. (2007). "Comparison of athletes'personality traits in individual and team sports." Journal of Psychological Sciences, Volume 6, Issue 23.

[5] Pare, A. (2010). "The effect of physical activity on psychological health profile of juvenile offenders". Master thesis, Islamic Azad University of Tehran.

[6] Dimateo, UM. R. (2008). "health Psychology". A translation by a group of authors in Research Institute of seminary and university under the supervision of K Hashemian, University Publication, Tehran, vol. 1.

[7] Sarvari, R. (2005). 'A practical guide of mental exercises to peak performance ". First edition, Tehran: for Publishing Research Institute of Noor.

[8] Shahintaba', M. (2010). "The effects of psychological interventions on personality profile, emotional intelligence, Competitive State Anxiety and athletic performance of elite basketball players." Doctoral dissertation on motor behavior, University of ShahidBeheshti.

[9] Shahintaba', M., Aslankhani, MA., Abdoli, B., Kamkari, K. (2010). "The impact of a psycho-educational program on mental health of elite basketball players." motor -sport growth and learning, Issue 5, pp. 29-47.

[10] Sadeghi, R. (2007). "The level of their physical fitness by step test and amount of individual's maximal aerobic power". Research project.

[11] Abbasi, J. (2010). "Is exercise effective on improving mental states?", Today Psychology Publication.

[12] Azizian, G. (2010). "The effects of intelligence profile and mental health on the performance of Iranian elite female basketball players in quintetposts ". Master thesis, Islamic Azad University of Tehran.

[13] Fazelbakhshi, A. (2007). "The relationship between physical activity and self-imagination in athletes and non-athletes ". Research project.

[14] Kamkari, K.,Shokrzadeh, Sh. (2007). "Comparing personality traits and hardiness of professional and amateur basketball players." Research project.

[15] Moradinezhad, M. (2003). "The effects of physical activity on teenagers' mental health ". Research project.

[16] Nawabi, Sh. (2008). "A study on personality traits of elite chess players," MA thesis, Islamic Azad University of Tehran.

[17] Nvabinezhad, SH. (2009). "Study of female athletes'psychological traits participating in the national championships." Deputy of women sport, Research Association.

[18] Noshadiyan, K. (2011). "A comparative study on mental health indicators and cognitive abilities in both active and passive protagonistsin basketball", Master thesis, Islamic Azad University of Tehran.

[19] Waezmousavi, MK., Shojaei, A. (2003). "Sport psychology". Second edition, Tehran: SamtPublication.

[20] Bredemeier, B.L. Shields, D.L. (2006). "Sports and character development". Research diges, Vol: 7(1), PP: $1-8$. 

Team

[21] Corsiny, Raymond. (2004). "The dictionary of psychology”. P: Brunner/Mazel. 3rd edition.

[22] Day, Arla L\& Carroll, Sarah A. (2004). "Using an ability-based measure of emotional intelligence to predict individual performance, group performance, and group citizenship behaviors". science direct. Vol (36), issue 6. PP: 1443-1458 .

Citation: Sholeh khodadad kashi. "A Study on Mental Health Profile of Athletes and Technical Staff of Iranian Women's National Swimming Team." International Journal of Sports and Physical Education (IJSPE), vol 3, no. 4, 2017, pp. 32-39. doi:http://dx.doi.org/10.20431/2454-6380.0304006.

Copyright: (C) 2017 Authors. This is an open-access article distributed under the terms of the Creative Commons Attribution License, which permits unrestricted use, distribution, and reproduction in any medium, provided the original author and source are credited. 